NBER WORKING PAPER SERIES

\title{
SUPPORT FOR PAID FAMILY LEAVE AMONG SMALL EMPLOYERS INCREASES DURING THE COVID-19 PANDEMIC
}

\author{
Ann P. Bartel \\ Maya Rossin-Slater \\ Christopher J. Ruhm \\ Meredith Slopen \\ Jane Waldfogel \\ Working Paper 29486 \\ http://www.nber.org/papers/w29486
}

\section{NATIONAL BUREAU OF ECONOMIC RESEARCH \\ 1050 Massachusetts Avenue \\ Cambridge, MA 02138}

November 2021, Revised December 2021

This article is published at Socius: Sociological Research for a Dynamic World (Volume 7, p. 1-8, Dec. 2021, https://doi.org/10.1177\%2F23780231211061959). We gratefully acknowledge funding for this research from Pivotal Ventures, Washington Center for Equitable Growth, Russell Sage Foundation, and Ford Foundation, and support from the Columbia Population Research Center which is funded by the National Institute for Child Health and Human Development (NICHD) through grant P2CHD058486. The views expressed herein are those of the authors and do not necessarily reflect the views of the National Bureau of Economic Research.

NBER working papers are circulated for discussion and comment purposes. They have not been peer-reviewed or been subject to the review by the NBER Board of Directors that accompanies official NBER publications.

(C) 2021 by Ann P. Bartel, Maya Rossin-Slater, Christopher J. Ruhm, Meredith Slopen, and Jane Waldfogel. All rights reserved. Short sections of text, not to exceed two paragraphs, may be quoted without explicit permission provided that full credit, including $(\subset)$ notice, is given to the source. 
Support for Paid Family Leave among Small Employers Increases during the COVID-19 Pandemic Ann P. Bartel, Maya Rossin-Slater, Christopher J. Ruhm, Meredith Slopen, and Jane Waldfogel NBER Working Paper No. 29486

November 2021, Revised December 2021

JEL No. H50,I18,I38,J38

\section{ABSTRACT}

The United States is one of the few countries that does not guarantee paid family leave (PFL) to workers. Proposals for PFL legislation are often met with opposition from employer organizations, who fear disruptions to business, especially among small employers. But there has been limited data on employers' views. We surveyed firms with 10-99 employees in New York and New Jersey on their attitudes towards PFL programs before and during the COVID-19 pandemic. We found high support for state PFL programs in 2019 that rose substantially over the course of the pandemic: by the fall of 2020, almost $70 \%$ of firms were supportive. Increases in support were larger among firms that had an employee use PFL, suggesting that experience with PFL led to employers becoming more supportive. Thus, concerns about negative impacts on small employers should not impede efforts to expand PFL at the state or federal levels.

Ann P. Bartel

Graduate School of Business

Columbia University

3022 Broadway, 623 Uris Hall

New York, NY 10027

and NBER

apb2@columbia.edu

Maya Rossin-Slater

Department of Health Policy

Stanford University School of Medicine

615 Crothers Way

Encina Commons, MC 6019

Stanford, CA 94305-6006

and NBER

mrossin@stanford.edu

Christopher J. Ruhm

Frank Batten School of

Leadership and Public Policy

University of Virginia

235 McCormick Rd.

P.O. Box 400893

Charlottesville, VA 22904-4893

and NBER

ruhm@virginia.edu
Meredith Slopen

Columbia University

School of Social Work

1255 Amsterdam Ave

New York, NY 10027

mes2004@columbia.edu

Jane Waldfogel

Columbia University

School of Social Work

1255 Amsterdam Avenue

New York, NY 10027

jw205@columbia.edu 


\title{
Support for Paid Family Leave among Small Employers Increases during the COVID-19 Pandemic $^{*}$
}

\author{
Ann Bartel, Maya Rossin-Slater, Christopher Ruhm, Meredith Slopen, Jane \\ Waldfogel ${ }^{* *}$
}

December 2021

\begin{abstract}
The United States is one of the few countries that does not guarantee paid family leave (PFL) to workers. Proposals for PFL legislation are often met with opposition from employer organizations, who fear disruptions to business, especially among small employers. But there has been limited data on employers' views. We surveyed firms with 10-99 employees in New York and New Jersey on their attitudes towards PFL programs before and during the COVID-19 pandemic. We found high support for state PFL programs in 2019 that rose substantially over the course of the pandemic: by the fall of 2020, almost $70 \%$ of firms were supportive. Increases in support were larger among firms that had an employee use PFL, suggesting that experience with PFL led to employers becoming more supportive. Thus, concerns about negative impacts on small employers should not impede efforts to expand PFL at the state or federal levels.
\end{abstract}

Keywords: paid family leave; COVID-19; small business; employer attitudes; employer surveys

\section{Introduction}

The United States stands out from peer countries in not mandating rights to paid family leave (PFL) when employees need to be absent from work to care for a new child or a seriously ill family member, although the federal Family and Medical Leave Act (FMLA) does provide 12 weeks of unpaid leave to some workers employed at firms with 50 or

* This article is published at Socius: Sociological Research for a Dynamic World (Volume 7, p. 18, Dec. 2021, https://doi.org/10.1177\%2F23780231211061959). We gratefully acknowledge funding for this research from Pivotal Ventures, Washington Center for Equitable Growth, Russell Sage Foundation, and Ford Foundation, and support from the Columbia Population Research Center which is funded by the National Institute for Child Health and Human Development (NICHD) through grant P2CHD058486.

** Bartel: Columbia Business School and NBER; e-mail: apb2@gsb.columbia.edu; Rossin-Slater: Stanford University School of Medicine; NBER; IZA; e-mail: mrossin@stanford.edu; Ruhm: University of Virginia; NBER; IZA; e-mail: ruhm@virginia.edu; Slopen: Columbia University School of Social Work; e-mail: mes2004@columbia.edu; Waldfogel: Columbia University School of Social Work; London School of Economics; IZA; e-mail: jw205@columbia.edu 
more employees. In the absence of a federal program, ten states have enacted their own PFL programs, beginning with California whose law took effect in 2004 (National Partnership for Women and Families 2020).

The COVID-19 pandemic amplified the need that workers have for paid and job-protected leave to care for family members (in addition to paid sick leave for their own illness). During the pandemic, PFL was introduced temporarily at the federal level through the Families First Coronavirus Response Act (FFCRA), and state PFL laws programs were amended to cover COVID-19-related absences. A new federal PFL program has been proposed as part of the Build Back Better bill. ${ }^{1}$

Polling data indicate that $84 \%$ of American voters strongly support PFL (National Partnership for Women and Families 2018). However, employer organizations have often opposed these policies fearing possible disruptions and costs to business, particularly for smaller employers (National Federation of Independent Business (NFIB) 2016). Surveys of individual employers, while rare, provide little evidence justifying these concerns. An important early study indicated that California's PFL program had positive or neutral effects on employee productivity, morale, and costs (Appelbaum and Milkman 2011). A more recent investigation suggests that New York's program improved small employers' ease in handling long employee absences (Bartel et al. 2021). However, very little is known about the attitudes of employers - especially small employers - with respect to PFL. In their foundational work Leaves that Pay, Appelbaum and Milkman found that firms reported little negative impact following the adoption of California's paid leave policy, but did not report on the level of support for the policy held by the firms more generally. Other researchers have reported positive employer attitudes in a small sample of firms from RI (Bartel et al., 2016).

The COVID-19 pandemic amplified the need for and use of paid leave (Boyens, 2020), increasing attention to paid leave policies nationally. It is possible that this heightened awareness changed attitudes towards PFL among employers. However, although small employers are critical stakeholders, little is known about how small employers view PFL policies and whether their attitudes toward such policies changed during the pandemic. Thus, we estimate a model to determine whether employer attitudes changed from fall 2019 to fall 2020.

If employers did become more supportive of PFL during the pandemic, it is important to determine to what extent that change is constant or varies by the size of their workforce. Our sample includes very small firms with 10-49 employees as well as somewhat larger firms with 50-99 employees. We estimate separate models for these two firms size subgroups to see whether attitudes and the change in attitudes is similar or different across them.

Finally, if employers did become more supportive of PFL during the pandemic, it is important to know whether this increase in support extends to firms that had employees use paid leave or whether this support is confined to firms that did not have experience with PFL use. Thus, we analyze whether the change in attitudes of employers toward paid leave policies differs by whether the firm had any employees who took paid leave either

${ }^{1}$ Build Back Better legislation: https://www.congress.gov/bill/117th-congress/house-bill/5376. 
through the new federal program established under the Families First Coronavirus Response Act (FFRCA) or through state PFL policies.

This article provides new evidence on how small employers with 10-99 employees in New York and New Jersey view their states' PFL programs, with special attention to changes in attitudes during the COVID-19 pandemic. ${ }^{2}$ Both the New York and New Jersey state PFL programs apply to firms regardless of the number of employees, unlike FMLA which is only available to employees working in firms with 50 or more employees. Smaller firms are rarely included in employer surveys, and understanding their views is particularly important since their attitudes toward PFL are thought to be less favorable than those of their larger counterparts (NFIB 2016). We surveyed firms in the fall of 2019 and fall of 2020, just before and during the pandemic. Employer attitudes about PFL may be especially revealing since they summarize employers' overall impressions of the program rather than focusing only on specific aspects (such as employee performance on dimensions related to attendance or commitment to the job).

\section{Data and Methods}

The analysis in this article uses data from a survey that was originally designed to assess the impact of New York's 2018 Paid Family Leave Act. Drawing from business listings from Survey Sample Inc., we recruited a representative sample of firms with 10 to 99 employees in New York and New Jersey in 2016. In 2017, 2018, and 2019 we re-contacted as many firms as possible and also recruited new firms to maintain the sample's size and representativeness. In 2020 we again re-contacted as many firms as possible but did not recruit any new firms. The sample was drawn and contacted by the Office of Survey Research (OSR) at Michigan State University. Our analysis focuses on whether employers stated that their attitudes towards their state's PFL program were: very or somewhat supportive (denoted as "supportive" below); neutral; or somewhat or very opposed (denoted as "opposed"). In the fall of 2020, we also asked employers whether they had any employees who used federal PFL through the FFCRA and whether they had any employees who used their state PFL program during the last 12 months. The survey was conducted by OSR and approved by the relevant University Institutional Review Board. Data and code used in the study are accessible at: https://github.com/MSlopen/NYEmployerStudy Socius2021.

The original survey sample was representative of firms in three size categories (10-19, 20-49, and 50-99 employees, respectively) and in 16 sectors based on the North American Industry Classification System (NAICS) code categories. Initial contact was made by mail, with follow-ups via mail, phone, and e-mail. In each firm, the owner or manager completed the survey. The initial response rate (in 2016) was 46\%. The survey included a question about the respondent's attitude toward their state's PFL policy on a five-point Likert scale (very supportive $=5$, somewhat supportive $=4$, neutral $=3$, somewhat opposed $=2$, and very

\footnotetext{
${ }^{2}$ New Jersey's policy offered a weekly benefit rate of $66 \%$ of a worker's average weekly wage (AWW) to a maximum benefit of $\$ 650$ in 2019 for up to 6 weeks and was expanded in 2020 to offer a weekly benefit rate of $85 \%$ of the worker's AWW, up to a maximum of $70 \%$ of the statewide AWW for 12 weeks. New York is in the process of phasing in their PFL policy: in 2019 and 2020 workers were entitled to 10 weeks at $55 \%$ of the worker's salary up to $55 \%$ of the state AWW, increasing to $60 \%$ of the worker's salary up to $60 \%$ of the state AWW in 2020 . Both state policies include job protection consistent with FMLA.
} 
opposed=1), as well as questions about employee composition and performance. We collapsed the responses about attitudes into three categories: supportive (including very and somewhat supportive), neutral, and opposed (including very and somewhat opposed).

To understand employers' experiences during the COVID-19 pandemic, in fall 2020, we attempted to recontact all 4711 firms who had participated in prior waves. A total of 1151 firms responded, for a response rate of 24.4\%. Among the 1151 firms, 264 firms had closed in the intervening period and 887 firms were operational at the time of response. Of the 887 firms that were operational, 539 responded to the employer attitude and leave use questions in both 2019 and 2020 and were included in the analytic sample for this paper. We have compared our analytic sample $(\mathrm{N}=539)$ to our initial representative sample from $2016(\mathrm{~N}=2400)$ and to our 2019 sample $(\mathrm{N}=2428)$. Our analytic sample does not differ from the initial representative sample with respect to the distribution by industrial sector except for Other Services and Transportation and Warehousing, while no significant differences by sector are observed when comparing our analytic sample to the 2019 representative sample. However, firms with 50-99 employees are under-represented in the analytic sample while firms with 10-49 employees are over-represented, relative to their proportions in the initial representative sample and in the 2019 sample. See Appendix Table 1 which shows the results of these comparisons.

Our first research question is whether employer attitudes changed from fall 2019 to fall 2020. We address this using Ordinary Least Squares (OLS) regression models with firm fixed effects. Inference was conducted using heteroskedasticity-robust standard errors. The regression model takes the following form:

$$
\text { Attitude }_{i t}=\beta_{0}+\beta_{1} 2020_{t}+\gamma_{i}+X_{i t}+\varepsilon_{i t}(1)
$$

where Attitude $_{i t}$ is an indicator set to 1 if firm $i$ is supportive of (or opposed to) their state PFL policy in year $t ; 2020_{t}$ is an indicator set to 1 in 2020 and 0 in 2019; $\gamma_{i}$ is the firm fixed effect that controls for all time-invariant characteristics of the firm; and $X_{i t}$ is a vector of time-varying firm characteristics including the number of employees, the share of employees who work part-time, the share of employees who are female, the share of employees who worked at the firm for more than one year, the share of employees who were absent without notice in the past 30 days, and the share of employees who quit in the past year.

Our second research question is whether attitudes and changes in attitudes differed by firm size. This analysis is important given that attitudes may vary by firm size and given the under-representation of firms with 50-99 employees in our analytic sample. Thus, we also estimated model (1) separately in subsamples stratified by two firm size categories to compare changes among firms with 10-49 employees and those among firms with 5099 employees. The key coefficient of interest is $\beta_{1}$, which measures the change in firms' attitudes toward PFL during fall 2020 relative to the year before. Figure 1 provides the distribution of firms' attitudes toward their states' PFL program by year. Figure 2 provides the regression coefficients and 95 percent confidence intervals from the adjusted models.

Our third research question is whether the firms' reported use of state PFL policies and the federal FFCRA policy was associated with changes in firms' attitudes toward PFL. Understanding whether having an employee use the policy is associated with increased support or opposition provides a robustness check as to whether changes in attitudes are 
seen in firms that actually had experience with PFL. We could not include firm fixed effects in these analyses, since the variables about PFL and FFCRA use are only available for each firm once. We therefore estimated OLS regression models that included controls for the firm's level of support in 2019 (i.e., before the pandemic), state fixed effects, industrial sector fixed effects, and the same firm composition control variables as in regression model (1), measured in 2019. This model takes the form:

Attitude $_{i}^{2020}=\beta_{0}+\beta_{1}$ FFCRA $_{i}+\beta_{2}$ StatePol $_{i}+\beta_{3} N Y_{i}+\beta_{4}$ Attitude $_{i}^{2019}+\beta_{5}$ Sector $_{i}+$ $X_{i}+\varepsilon_{i}$

where Attitude $e_{i}^{2020}$ is an indicator set to 1 if firm $i$ is supportive of (or opposed to) their state PFL policy in 2020 and 0 otherwise; $F F C R A_{i}$ is an indicator set to 1 if a firm had at least one employee who used the federal paid leave policy and 0 otherwise; StatePol $_{i}$ is an indicator set to 1 if a firm had at least one employee who used the state PFL policy and 0 otherwise; $N Y_{i}$ is an indicator for firms located in New York and 0 for firms located in New Jersey; Attitude $_{i}^{2019}$ is an indicator set to 1 if firm $i$ is supportive (or opposed to) their state PFL policy in 2019 and 0 otherwise; Sector $_{i}$ is a set of 16 indicators for industrial sectors of the firm; and $X_{i}$ is the vector of firm characteristics as in model (1), measured in 2019. The key coefficients of interest are $\beta_{1}$ and $\beta_{2}$, which measure the association between a firm having an employee use the federal and state PFL policies during 2020 and its support or opposition to the state PFL policy.

We also estimated model (2) using subsamples stratified by two firm size categories to compare changes among firms with 10-49 employees and those with 50-99 employees. Figure 3 provides the coefficients and 95\% confidence intervals for the association between the reported use of each policy $\left(\beta_{1}\right.$ and $\left.\beta_{2}\right)$ and support for PFL in 2020 for all firms, firms with 10-49 employees, and firms with 50-99 employees.

\section{Results}

Employer support increased during the COVID-19 pandemic. Among employers interviewed in both fall 2019 and fall 2020, the share reporting that they were very or somewhat supportive of PFL rose by 9.1 percentage points, from $61.6 \%$ to $70.7 \%$ (Figure 1). The corresponding share of firms who were somewhat or very opposed to PFL declined by 9.6 points, from $20.0 \%$ to $10.4 \%$. Considering firms by size, in 2019 , firms with $50-99$ employees had more favorable views of PFL than firms with $10-49$ employees: $68.3 \%$ of the former were supportive, compared to $58.7 \%$ of the latter.

After adjusting for firm fixed effects as well as firm time-varying covariates (such as percent of employees who worked part-time or were female), the increase in support was 9.6 percentage points $(p<0.01)$ and the adjusted reduction in opposition was $8.8 \%(p<0.01)$ (Figure 2, Appendix Table 2). A significant 14.6 percentage point $(p=0.02)$ increase in support and a 13.5 percentage point $(p=0.01)$ reduction in opposition to PFL was observed among firms with 50-99 employers.

However, it would be a mistake to conclude that smaller employers with 10-49 employees are opposed to PFL. To the contrary, in 2019, they were 2.5 times more likely to support than to oppose PFL (58.7\% versus $20.9 \%$ ), and support increased by an unadjusted 10.6 percentage points (Figure 1$)$ and a regression-adjusted 7.5 percentage points $(p=0.04)$ 
from 2019 to 2020, with analogous 10.0 and $8.2(p<0.01)$ percentage point decreases in the percentage of small firms opposing PFL (Figure 2, Appendix Table 2).

Use of PFL during COVID-19 was associated with greater support. Among employers interviewed in both 2019 and 2020, 21.9\% reported in 2020 that they had an employee who used state PFL during the last year and $28.6 \%$ reported that they had an employee who used the federal FFCRA. ${ }^{3}$ As shown in Figure 3, reported employee use of state PFL was associated with a rise in employer support for the program: by a regression-adjusted 9.7 percentage points $(p=0.03)$, a $16 \%$ increase from the 2019 baseline support level of $61.6 \%$. Use of FFCRA was not significantly associated with changes in support for state PFL. Use of either type of leave reduced the percentage of firms opposing the state PFL policy by smaller amounts with the FFCRA predicted effect again not being statistically significant.

We also estimated models by firm size. Support for state PFL laws rose by a regressionadjusted 14.1 percentage points ( $p=0.01$ ) among employers with 10-49 employees and with an employee who had used state PFL, an increase of $24 \%$ from the pre-COVID-19 baseline of $58.7 \%$. Conversely, while use of the state program was not associated with changes in favorability ratings among employers with 50-99 employees, worker use of FFCRA leave was associated with a 12.8 percentage point increase $(p=0.10)$, corresponding to a $19 \%$ growth from the baseline support level of $68.3 \%$. Use of either program decreased the likelihood that employers in both firm size groups opposed state PFL programs, but these reductions were smaller in magnitude and not statistically significant. Coefficients are shown in Appendix Table 3.

\section{Discussion}

The COVID-19 pandemic highlighted the potential role of programs providing paid and job-protected leave for employees who need to be absent from work for their own illness or to care for family members. Thus, both paid sick leave and paid family leave are receiving heightened attention on the public policy agenda. Recent analyses have documented the use of paid sick leave during COVID-19 (Andersen et al. 2020; Pichler, Wen, and Ziebarth 2020) but we know less about PFL and the pandemic (Boyens 2020).

Drawing on data collected immediately prior to and during the COVID-19 pandemic, we provide new evidence on employer attitudes towards state PFL programs. Attitudes provide useful information because they summarize employers' overall experiences with the programs, which may be imperfectly or incompletely revealed by responses to questions focused on specific aspects of the programs or hard-to-measure factors such as productivity.

Our analysis focuses on firms with 10-99 employees, since opponents of PFL often argue that small employers are most adversely affected by PFL. Drawing on a survey conducted in fall 2019 and fall 2020 in New York and New Jersey, we find that employer support for PFL, which was already high in 2019 , increased significantly during COVID-19. Moreover, reported use of the state PFL program during the prior year was associated with greater

${ }^{3} 56.8 \%$ of employers reported they did not have any workers use FFCRA and $14.7 \%$ did not provide information on FFCRA use. Similarly, $56.8 \%$ of firms reported no use of state leave programs and $21.7 \%$ did not respond to the state PFL use questions. 
support for PFL, holding constant the employer's level of support before COVID-19. This suggests that as employers gain familiarity with the programs their support tends to increase and opposition decreases.

Our findings that small employers largely support PFL policies and that such support increased during the pandemic make an important contribution to the literature. However, there are a number of limitations that should be noted and addressed in future research. The sample of firms included in this analysis is relatively small and, while our analytic sample maintains representation of the industrial mix within each state, smaller firms with 10-49 employees are over-represented, perhaps because managers of the firms with 5099 employees were more likely to be working remotely and thus more difficult to reach. The over-representation of firms with 10-49 employees, who are somewhat less supportive of PFL and experience somewhat less of an increase in that support from 2019 to 2020, means that our estimates for the overall sample understate both the level and increase in support among firms with 10-99 employees. We have addressed this by providing separate results by firm size but future studies should endeavor to include larger and more representative samples. In addition, there are limits to the types of firm-level characteristics that were available to include in this analysis. Finally, as data is selfreported by the firm's owner or manager, there could be reporting errors by respondents.

In spite of these limitations, our results have implications for the current policy debate. First, contrary to some commonly-cited rhetoric, small employers in states with PFL programs are actually quite supportive of PFL, suggesting that concerns about negative impacts on such firms should not be an impediment to enacting PFL programs. Second, support among these firms increased during COVID-19, while opposition decreased, indicating that the post-COVID-19 period could be an opportune moment for considering further related legislation, such as the federal Build Back Better bill. In addition, this finding of increased support highlights the role of PFL as a form of social insurance, which become particularly desirable during periods of social or economic distress. Third, employers who experienced having workers use PFL during the pandemic became more supportive of the programs, suggesting that their experiences were positive. 


\section{References}

Andersen, Martin, Johanna Catherine Maclean, Michael Pesko, and Kosali Simon. 2020. Effect of a Federal Paid Sick Leave Mandate on Working and Staying at Home: Evidence from Cellular Device Data. w27138. Cambridge, MA: National Bureau of Economic Research. doi: 10.3386/w27138.

Appelbaum, Eileen, and Ruth Milkman. 2011. Leaves That Pay: Employer and Worker Experiences with Paid Family Leave in California. Center for Economic and Policy Research.

Bartel, Ann P., Maya Rossin-Slater, Christopher J. Ruhm, Meredith Slopen, and Jane Waldfogel. 2021. The Impact of Paid Family Leave on Employers: Evidence from New York. Working Paper. 28672. National Bureau of Economic Research. doi: 10.3386/w28672.

Bartel, Ann, Maya Rossin-Slater, Christopher Ruhm, and Jane Waldfogel. 2016. Assessing Rhode Island's Temporary Caregiver Insurance Act: Insights from a Survey of Employers. US Department of Labor, Chief Evaluation Office.

Boyens, Chantel. 2020. "State Paid Family and Medical Leave Programs Helped a Surge of Workers Affected by the COVID-19 Pandemic." Urban Institute. Retrieved July 22, 2020 (https://www.urban.org/research/publication/state-paidfamily-and-medical-leave-programs-helped-surge-workers-affected-covid-19pandemic).

National Federation of Independent Business (NFIB). 2016. "The Unintended Consequences of Paid Family Leave." NFIB. Retrieved June 22, 2021 (https://www.nfib.com/content/analysis/economy/the-unintended-consequencesof-paid-family-leave-74925/).

National Partnership for Women and Families. 2018. Voters' Views on Paid Family and Medical Leave: Findings from a National Survey.

National Partnership for Women and Families. 2020. "Paid Sick Days - State and District Statutes." Retrieved May 6, 2020 (https://www.nationalpartnership.org/ourwork/resources/economic-justice/paid-sick-days/paid-sick-days-statutes.pdf).

Pichler, Stefan, Katherine Wen, and Nicolas R. Ziebarth. 2020. "COVID-19 Emergency Sick Leave Has Helped Flatten The Curve In The United States." Health Affairs 10.1377/hlthaff.2020.00863. doi: 10.1377/hlthaff.2020.00863. 


\section{Figures}

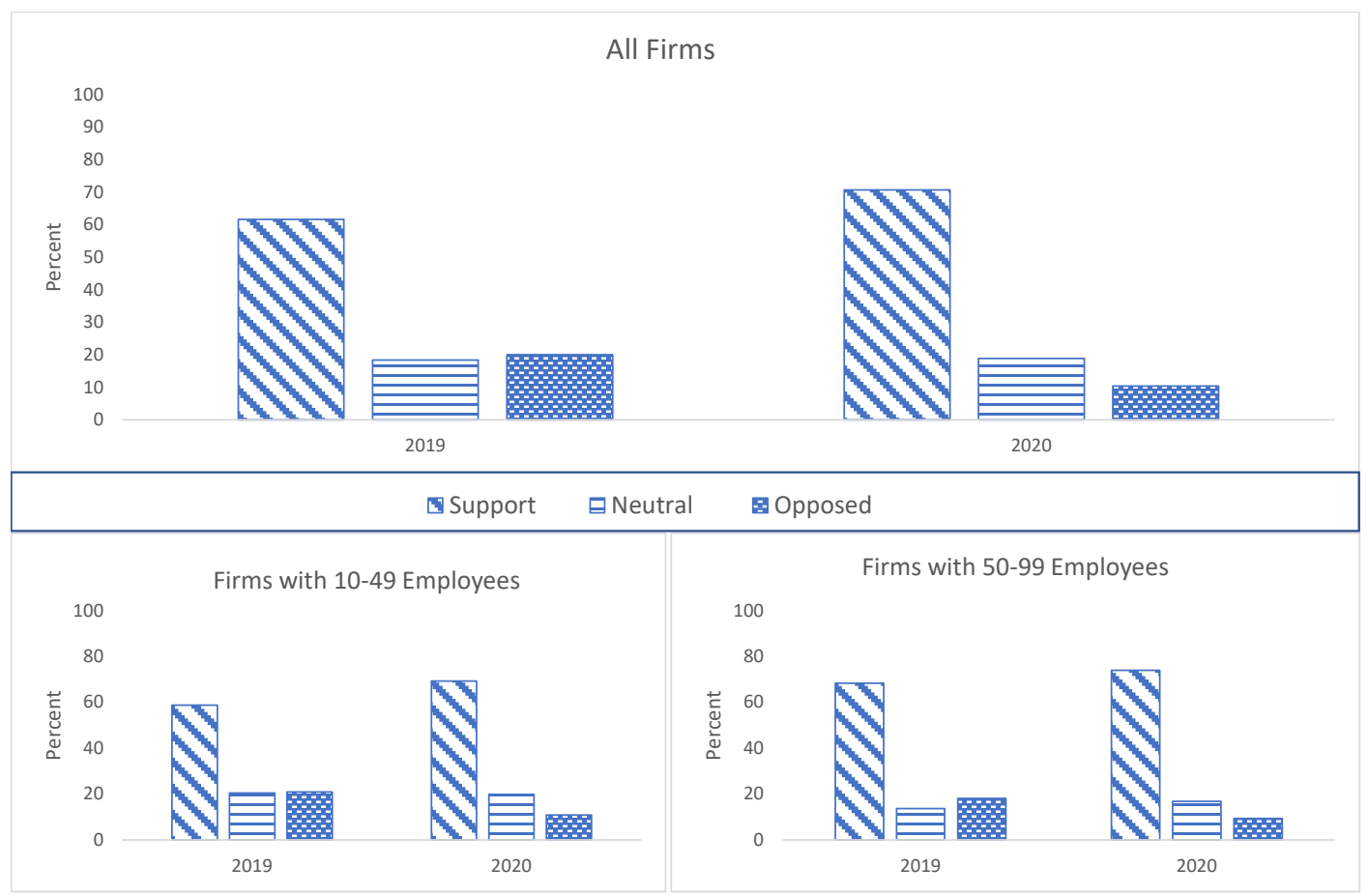

Figure 1. Within-Firm Changes in Support for and Opposition to State Paid Family Leave between 2019 and 2020 in New York and New Jersey

Notes: Columns represent the percent of firms who report that they are supportive, neutral or opposed to PFL policies in 2019 and 2020. N=539 firms. 


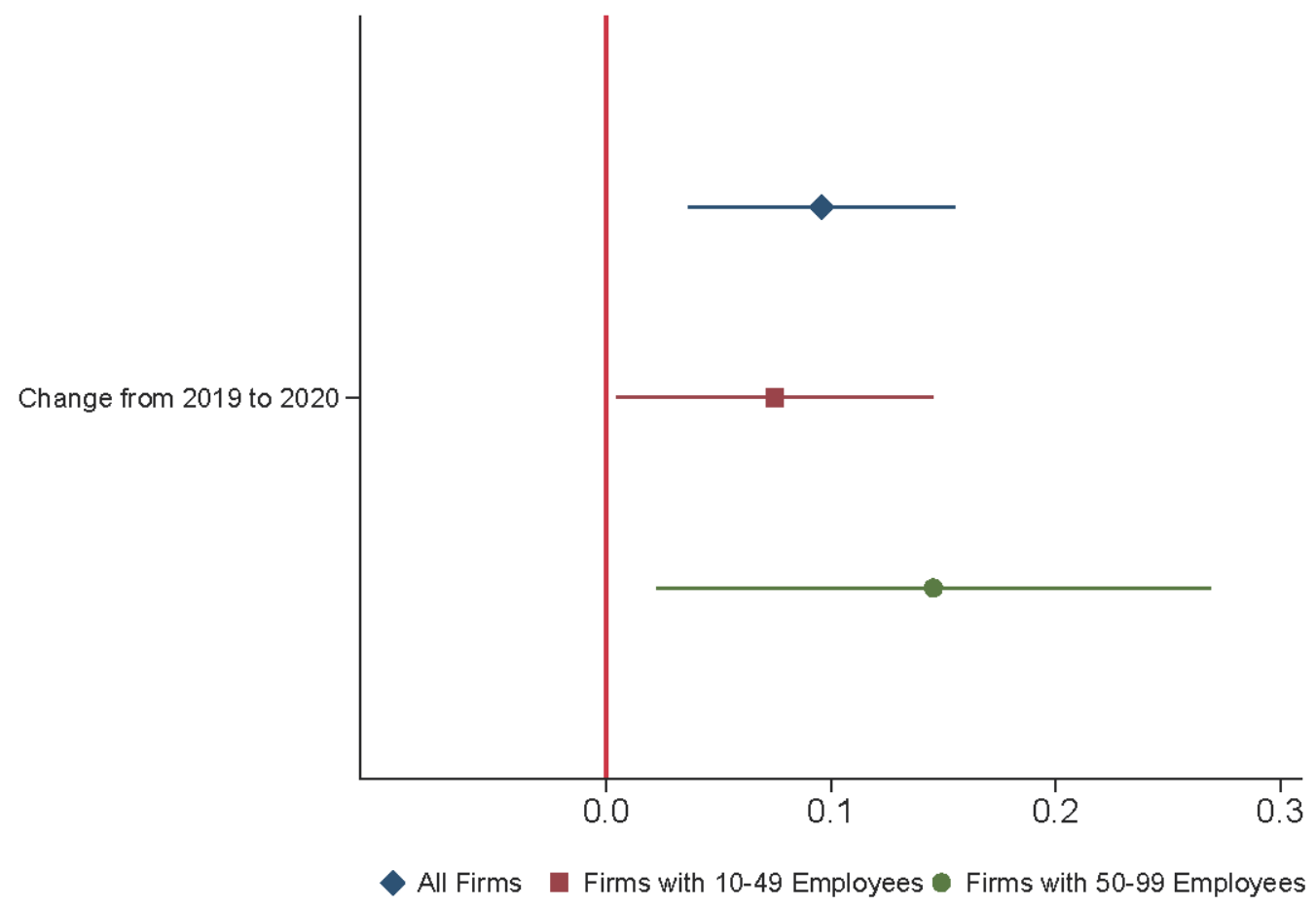

Figure 2: Within-Firm Changes in Support for and Opposition to State Paid Family Leave between 2019 and 2020 in New York and New Jersey

Notes: The figure reports the regression coefficients and associated 95\% confidence intervals from regression models that analyze within-firm changes in support for the state PFL policy between 2019 and 2020. Markers represent coefficient point estimates; lines provide the 95\% confidence intervals. Regression coefficients and 95\% confidence intervals are derived from linear regression models controlling for firm fixed-effects, firm composition, and industrial sector (Equation 2). The blue diamond denotes the coefficient from the model estimated on the sample of all firms; the red square denotes the coefficient from the model estimated on the sample of firms with 10 to 49 employees; the green circle denotes the coefficient from the model estimated on the sample of firms with 50 to 99 employees. $\mathrm{N}=539$ firms. 


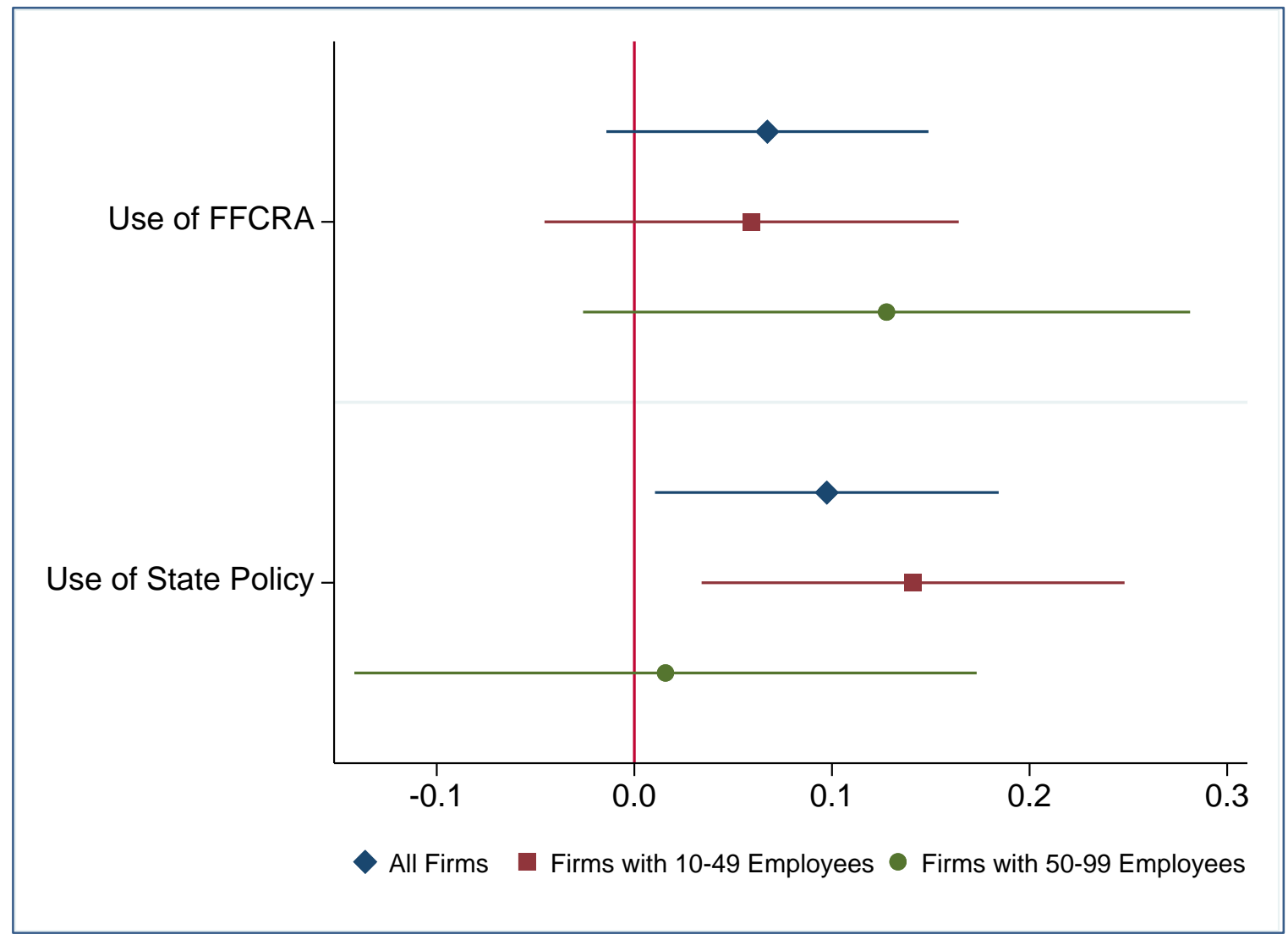

Figure 3. Association between the Use of Leave Policies and Change in Support for State PFL

Notes: The figure reports the regression coefficients and associated $95 \%$ confidence intervals from regression models that analyze the association between firms' use of federal and state leave policies and the change in their support for the state PFL policy between 2019 and 2020. Markers represent coefficient point estimates; lines provide the $95 \%$ confidence intervals. Regression coefficients and 95\% confidence intervals are derived from linear regression models controlling for the firms support level in 2019, firm composition, and industrial sector (Equation 2). The blue diamond denotes the coefficient from the model estimated on the sample of all firms; the red square denotes the coefficient from the model estimated on the sample of firms with 10 to 49 employees; the green circle denotes the coefficient from the model estimated on the sample of firms with 50 to 99 employees. $\mathrm{N}=539$ firms. 


\section{Appendix}

Appendix Table 1. Comparison of Analytic Sample to 2016 and 2019 Representative Samples

\begin{tabular}{|c|c|c|c|c|c|}
\hline & $\begin{array}{l}\text { Analytic } \\
\text { Sample }\end{array}$ & $\begin{array}{c}2016 \\
\text { Sample }\end{array}$ & $\begin{array}{c}\text { Significantly } \\
\text { Different } \\
\text { than } \\
\text { Analytic } \\
\text { Sample } \\
\end{array}$ & $\begin{array}{c}2019 \\
\text { Sample }\end{array}$ & $\begin{array}{c}\text { Significantly } \\
\text { Different } \\
\text { than } \\
\text { Analytic } \\
\text { Sample } \\
\end{array}$ \\
\hline \multicolumn{6}{|l|}{ Firm Size } \\
\hline $10-49$ & 70.1 & 57.0 & Ref & 52.2 & ref \\
\hline$\geq 50$ & 29.9 & 43.0 & $* * *$ & 47.8 & $* * *$ \\
\hline \multicolumn{6}{|l|}{ Sector } \\
\hline Accommodation and Food Services & 9.7 & 11.7 & Ref & 9.0 & ref \\
\hline $\begin{array}{l}\text { Administrative Support and Waste } \\
\text { Management }\end{array}$ & 4.5 & 4.0 & & 4.9 & \\
\hline Arts, Entertainment and Recreation & 2.2 & 2.5 & & 2.4 & \\
\hline Construction & 7.2 & 8.9 & & 8.1 & \\
\hline Finance and Insurance & 3.3 & 4.4 & & 4.8 & \\
\hline Health Care and Social Assistance & 14.1 & 13.0 & $*$ & 12.0 & \\
\hline Information & 2.8 & 4.5 & & 3.9 & \\
\hline Management of Companies and Enterprises & 0.0 & 0.4 & & 0.0 & \\
\hline Manufacturing & 13.7 & 13.6 & & 13.0 & \\
\hline $\begin{array}{l}\text { Mining, Quarrying and Oil and Gas } \\
\text { Extraction }\end{array}$ & 0.0 & 0.2 & & 0.2 & \\
\hline $\begin{array}{l}\text { Other Services (Except Public } \\
\text { Administration) }\end{array}$ & 10.2 & 6.5 & $* * *$ & 8.2 & \\
\hline Professional, Scientific and Technical & 15.6 & 13.9 & $*$ & 15.2 & \\
\hline Real Estate and Rental and Leasing & 1.5 & 1.9 & & 2.1 & \\
\hline Retail Trade & 5.6 & 5.2 & & 6.5 & \\
\hline Transportation and Warehousing & 2.8 & 1.6 & $* * *$ & 2.2 & \\
\hline Wholesale Trade & 6.9 & 7.8 & & 7.5 & \\
\hline $\mathbf{N}$ & 539 & 2954 & & 2428 & \\
\hline
\end{tabular}

Notes: ${ }^{\star} p<0.1,{ }^{\star \star} p<0.05,{ }^{\star \star \star} p<0.01$. 
Appendix Table 2. Changes in Support and Opposition for State Paid Leave Policies between 2019 and 2020, Controlling for Firm Fixed Effects and Composition

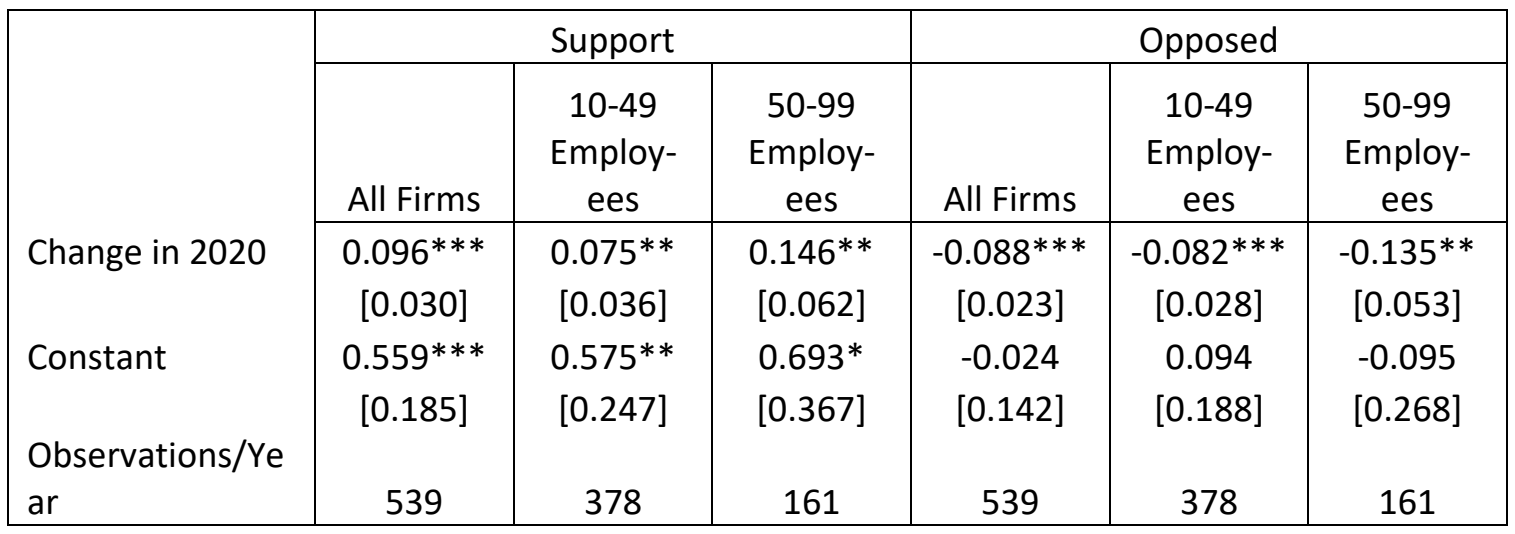

Notes: ${ }^{*} p<0.1,{ }^{* *} p<0.05,{ }^{* * *} p<0.01$. Standard errors in brackets. Regression coefficients are derived from OLS regression models controlling for firm fixed effects and firm composition variables $\left(\beta_{1}\right.$ from Equation 1$)$ and represent the percentage point change in the proportion of firms who support or oppose PFL between 2019 and 2020. N=539 firms.

Appendix Table 3. Association between the Use of Leave Policies and Change in Support for State PFL

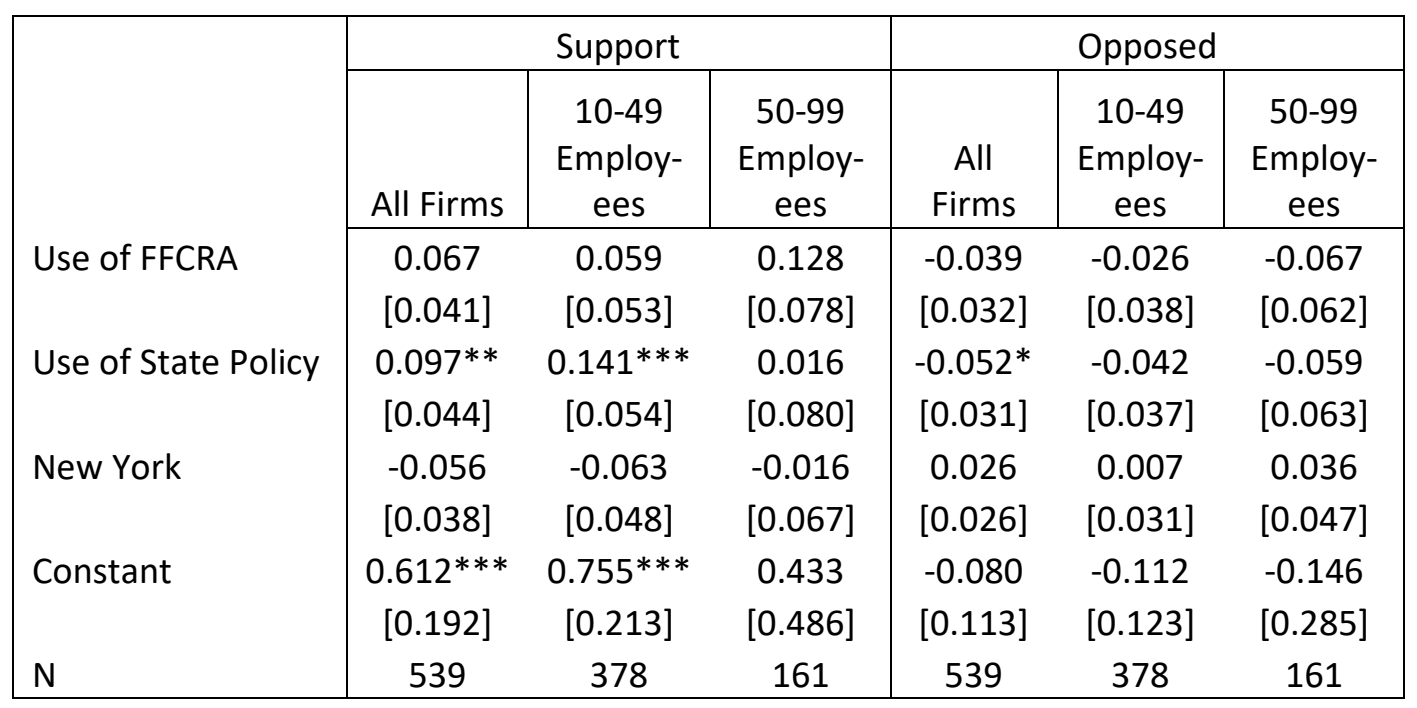

Notes: ${ }^{*} p<0.1,{ }^{* *} p<0.05,{ }^{* *} p<0.01$. Standard errors in brackets. Regression coefficients and $95 \%$ confidence intervals are derived from linear regression models controlling for the firms support level in 2019, firm composition, and industrial sector (Equation 2). N=539 firms. 